\title{
RETHINKING RESEARCH RELATIONSHIPS IN QUALITATIVE RESEARCH
}

\author{
TERRY L. MITCHELL \\ Memorial University \\ and \\ JOYCE L. RADFORD \\ Ontario Institute for Studies in Education
}

\begin{abstract}
The research relationship within qualitative research methods, that is, the relationship between researcher and research participant, is reexamined in this paper. We draw upon our own research experiences of working with high-risk individuals and vulnerable communities in reframing a discussion of the interview process. We illustrate the emotionally provocative and volatile nature of the research relationship and argue for the necessity of social research protocols which extend beyond a utilitarian research framework, the expansion of the researcher's role to include skillful navigation of the intersubjective aspects of research interviewing, and participant advocacy.
\end{abstract}

\section{INTRODUCTION}

In this paper we offer a preliminary exploration of the research relationship within qualitative research interviewing beginning with the premise that qualitative research, while well suited to the study of the personal and social, bears with it previously unexamined risks for the interviewee and, therefore, extended responsibilities for the researcher. Drawing from our experiences as social researchers we discuss interviewing practices within qualitative research with a focus on the intersubjective nature of the research relationship. We argue that both researcher and researched exist as subjects within the interview process, exist as participants in a relationship within which two subjectivities intersect. We extend the discussion of power and subjectivity central to the paradigm shift from positivist to postpositivist research to include a concern not only for the research product but also for the immediate interface of researcher and research participant.

Siedman states that "interviewing is both a research methodology and a social relationship, nurtured, sustained, and then ended gracefully" (1991, p. 72). He goes on to say that the sense of intimacy that develops within the research relationship increases the possibility of sexual exploitation on the part of the researcher. Siedman (1991) lends credence to our concerns regarding the highly charged nature of the research interview and our belief that the researcher, being in a position of greater power, has responsibilities to each research participant.

Correpondence can be directed to: Dr. Terry Mitchell, Sir Wilfred Grenfell College, University Drive, Comer Brook, NF A2H 6P9, tel. (709) 637-6440, mitchell/gmorgan ucs.mun.ea. 
Certainly, basic ethical principles demand that researchers violate neither the researcher's position of power nor the intimacy of the relationship (Kelman, 1972; Turnbull, McLeod, Callahan, \& Kessler, 1988).

In our discussion of intersubjectivity we argue that the qualitative research interview shares many of the qualities of the therapeutic interview and that the inclusion of the subjective within qualitative research necessitates acknowledgement of the emotional engagement of research participants and the emotional responses of researchers:

The research interview, while formally structured with the researcher seeking information and the interviewee providing information, is nevertheless organized in a conversational format (Berg, 1989) which brings the researcher and researched into relationship. "Thus, our knowledge is not a matter of uncovering, but rather one of conversing in an increasingly complex and enriching discussion" (Tolan, Chertok, Keys, \& Jason, 1990, p. 7). Due to a shared humanity, both researcher and participant are affected by this relationship. Van Manaan (1990, pp. 162-163), emphasizing the negative and positive impact of the research relationship on both researcher and researched, suggests that phenomenological research may have "lingering" effects on research participants, stating that "if done badly, these methods may instead lead to feelings of anger, disgust, defeat, intolerance, insensitivity, etc." and ultimately have "a transformative effect on the researcher himself or herself." We would add that while social researchers are often positively affected by their contact with research participants, the "social awakening" which occurs for some researchers within the research relationship can be very disturbing, even traumatic (see Mitchell \& Radford, 1995).

Acknowledging the powerful dynamics of the research relationship in indepth qualitative interviewing, we will address not only the essential goal of avoiding harm within the research relationship, we will also discuss the added responsibility of taking opportunities to benefit participants within the bounds of the research relationship and the necessity of specialized training for responsible inter-viewing. Knowing full well that it is not possible to pour new wine into old bottles without spoilage, we are suggesting a reevaluation of current qualitative research interviewing.

By virtue of the scope of our topic and the restraint an article demands, our discussion is a rather broad treatment of important methodological and ethical issues. The present article does not intend to present a well substantiated thesis but rather an overview of the complex methodological issues which are a part of our ongoing investigation of contemporary qualitative methods.

\section{THE RESEARCH RELATIONSHIP: CHALLENGING THE LIMITS OF "OBJECTIVITY"}

Researchers, such as Estroff (1981), Hall (1975), Maguire (1987), Oakley (1981), and Rabinow (1977) have written provocatively about the contradictions arising between their research practice and their personal beliefs and values. Contradictions identified by these new paradigm researchers were most often related to the traditional objectification of participants. For example, Oakley (1981) documented two difficulties in her interview work with mothers-to-be. First, she 
discovered that interviewees had legitimate and important questions they wanted answered, but concern over data bias due to "conversational" interruptions required that she avoid these opportunities to educate. Her second dilemma involved the intensity of the interviews which tended to establish a high degree of personal involvement between herself and the research participants. Oakley (1981) asserts that traditional interviewing protocols define the role of interviewees as subordinates with the "extraction of information" being more important than "yielding" it.

Traditional interviewing may leave researchers feeling as if they have objectified those whom they strive to understand and perhaps empower. This concern is raised by Siedman (1991, p. 81) who states that researchers who ignore or redirect sensitive or highly personal interview content "may signal to the participant that what is important to him or her is somehow not important to the interviewer." Siedman goes on to say that if a participant has risked mentioning a sensitive issue, it is important to acknowledge it and explore it. To do otherwise would be to predetermine the data, to signal to the participant the acceptable or anticipated content of the interview. In this manner, by not following the participant's lead in the interview the researcher risks confounding both the data and the participant.

Ely, Anzul, Friedman, Garner, and McCormack Steinmetz (1991) write of a moral and ethical struggle with "objectivity" in research interviewing. Ely et al. write of a feeling of having "used" people for research purposes. Traditional interview protocols instruct researchers to limit their conversation, their selfdisclosure, and their total engagement with research participants for fear of skewing the data. Interviewers like Oakley (1981) and Ely et al. (1991) raise concerns about disregarding the emotional and educational needs of their research participants.

Why have research procedures and training lagged behind researchers' felt experiences? One reason for this seems to be the continued concern for the validity and reliability of research data (see Lincoln \& Guba, 1985). Participatory research and critical ethnography have done a lot to address issues of ideology, voice, power, and subjectivity. Researchers who work within new paradigm research (Reason, 1988), or what is perhaps better known as post-positivist (Lincoln \& Guba, 1985) research, challenge the goal of objectivity. They ask themselves whose interests are served by a particular position rather than whether the data are biased (Lather, 1991). Not surprisingly, however, the fear of producing biased data continues to influence the interviewing procedures of new paradigm researchers. Researchers are generally not trained in the development and negotiation of research relationships yet they are warned about the line where necessary involvement ends and unwarranted involvement begins (Oakley, 1981). Researchers are taught that the interviewer's presence should not affect a respondent's perception of a question or answer, that the interviewer must act as a "neutral medium" with the primary purpose of recording information (Babbie, 1992).

The danger of over-identification with participants has remained a paramount concern for researchers because of the threat of confounded data. The postpositivist/new paradigm researcher's admission of values and "bias" is in direct 
contrast to the presumed stance of "objectivity" of the positivist researcher who maintains that researchers should distance themselves from personal feelings and involvement with participants. Within post-positivist research a different set of criteria (see Guba \& Lincoln, 1981; Lather, 1986; Reason \& Rowan, 1981) than the traditional, positivist framework must be used to establish the trustworthiness of the data. Walsh (1987) asserts that "knowledge gathering is an inherently interpersonal process that enhances not detracts from objectivity, since a research relationship of exchange strengthens both the internal and ecological validity of the investigation" (p. 781).

New paradigm researchers have acknowledged an identification with and respect for research participants but have, nevertheless, failed to specifically address the researcher's related responsibility to attend to the immediate needs of participants. The role of the interviewer is still being largely defined as a data gathering instrument. While the researcher's subjectivity is being acknowledged within new paradigm research, the responsibilities of researchers to their participants have not been adequately reexamined, nor are researchers' interviewing experiences being adequately drawn upon in the training of new interviewers.

Interviewers need to be prepared for greater responsibility and responsiveness in the research relationship at the level of the individual research participant. Research participants are more than data sources and researchers are more than data-collecting instruments; both researcher and participant are subjects engaged in a human relationship. If social researchers are concerned with social, as well as statistical outcomes, the interviewing process must reflect the relational quality of much social research (Rappaport, 1990).

\section{THE STRONG PARALLEL BETWEEN RESEARCH AND CLINICAL INTERVIEWING RESULTS IN UNSOLICITED DISCLOSURES BY PARTICIPANTS}

Researchers who have engaged in an in-depth, open-ended research interview process, and particularly if their work has involved sensitive topics, have undoubtedly experienced the surprise of receiving unsolicited and painful personal disclosures. As researchers ourselves, we have often received powerful and unanticipated disclosures from research participants. One of us discovered that we received more detailed disclosures, more quickly, in research interviews as compared to counselling interviews. The other received intense, unsolicited disclosures while interviewing street youth and when interviewing children who had witnessed their fathers beat their mothers.

Researchers should question what is appropriate behaviour, what are the appropriate responses and responsibilities of a researcher in a relationship where one person discloses personal, often private, and confidential aspects of their lives. The closest parallel to this relationship outside of the research frame is the therapeutic relationship. What can researchers learn from the experiences of therapists regarding appropriate responses and responsibilities? Would it be appropriate behaviour to ignore affect in a therapeutic interview? It seems that either researchers must change their methods so that they do not provide an illusion of a relationship with an interested, concerned, listener or conversely they must take the 
responsibility implicit in this relationship/role, for as Laing (1967. p. 53) stated, "If human beings are not studied as human beings than this once more is violence and mystification."

We do not use the word therapeutic to describe this new shift in the research relationship. There are obvious distinctions between social service and social research and we emphatically do not wish to conflate the two practices or to confuse their intentions. Rather, we wish to highlight points of convergence. There are, we have learned, many unacknowledged similarities between therapeutic and research interviews. High levels of disclosure accompanied by profound and potentially disruptive insights and emotional release are common responses to both the counselling and social research interview.

A beginning point in either the therapeutic or research relationship is for the professional to be a good listener. Research is, interestingly, one of the few contexts, other than therapy, where a person receives uninterrupted listening and skilled, interested attention. While the intention of the research interview is not therapeutic, it must be conceded that some of the same issues, concerns, and conditions arising in the therapeutic interview are implicit in the research process.

What, therefore, are the responsibilities of researchers for developing appropriate responses to interviewees when receiving personal and at times extremely painful disclosures? Engaging with interviewees as human respondents means treating them as individuals rather than as objects, as participants rather than data sources devoid of affect, that is, not as information sources which cease to exist when the tape recorder is turned off. Guidelines for interviewing (Babbie, 1992; Reid, Landesman Ramey, \& Burchinal, 1990) suggest exercising caution when probing research participants about potential unhappiness, distress, and trauma. By using the researcher's position of authority to redirect and control the interview process, interviewers are expected to keep unsolicited disclosures at bay and conveniently separated out of the interview process. Given the complex nature of diverse psychological and social realities, despite personal sensitivity and professionalism, researchers cannot reasonably predict how interview probes will affect interviewees.

Asking youth what is seemingly a simple demographic question such as, "Where do you live right now?" can erupt into an emotional account of the difficulties and traumatic episodes of their family life and those issues that may have forced them to leave their home. In essence, no interview question is simple and no answer predictable. The expectation that researchers should quash, ignore, or redirect sensitive disclosures seems ineffective at best in terms of data gathering and irresponsible at worst to the individual participant, especially when conducting research with individuals about sensitive topics.

Social researchers need to reflect upon the reasons why participants offer such detailed information on issues which have not, or rather have not explicitly, been requested. It has been suggested that personal disclosures result simply because participants perceive an opportunity to unburden themselves of information that has been causing them grief (Burgess, 1989). This, however, fails to account for the fact that interviewees are not disclosing to all community persons with whom they come into contact. While interviewing street youth, Radford was amazed by the 
number of young people who disclosed to her that their first sexual experience was one of child abuse. It might be argued that the interview had offered these youth an opportunity to finally purge themselves of the weighted secrecy of these traumatic events. The reality, however, was that these young people were typically "system kids": youth who had been under the direct care of child welfare workers for most of their lives.

Why was it that they so readily disclosed to her, as researcher, when they had not disclosed this information to anyone ever before? We do not assume that all of the community workers these youth encountered were unsympathetic, poor listeners, and experts at redirecting conversation. It is, however, possible that there is more to the research relationship than has previously been acknowledged.

What is it about the research relationship that makes participants want to disclose personal details that would otherwise be considered too risky to share? The answer to this question, at least in part, lies in the process of interviewing itself and the parallel between the research interview and the counselling interview. There is an identifiable congruence between the role and procedures of qualitative research interviewers and psychotherapists. If we consider what the elements of the successful interview are, we find the necessary components of interpersonal rapport, positive regard, trust, unconditional listening, and guaranteed anonymity. In effect, the face-to-face contact afforded the interviewer, resembles the interface between counsellors and their clients (Appelbaum \& Rosenbaum, 1989). A highly skilled research interviewer may be compared to the psychotherapist who uses nondirective comments and verbal probes to encourage free association and disclosure among their clients (Oakley, 1981). While good listening, support, potential catharsis, and/or increased self-awareness are the major returns research participation affords interviewees (Glesne \& Peshkin, 1992), a directed, reflective interview process is an intervention which has the potential to deeply affect interviewees and interviewers (Patton, 1990).

An obvious difference between the research interview and the therapeutic interview is the fact that most researchers have limited encounters with research participants. Perhaps it is for this very reason that researchers are selected as trusted confidants. The time-limited nature of the research relationship may contribute toward increased personal disclosure due to an increased sense of anonymity and freedom from consequence.

\section{EXTENDING THE RESPONSIBILITIES OF QUALITATIVE RESEARCHERS}

The interviewer, unwittingly chosen as a confidant, is afforded an opportunity to act as crisis intervener and educator with high-risk and hard-to-reach individuals, Research ethics demand that researchers minimize the potential harm that may come of interview participation (Turnbull et al. 1988); new paradigm methodologies also suggest that researchers work to neutralize the power differential which exists between researcher and participant. These standard professional guidelines, we propose, should be augmented to include researcher response and responsibility. 
As post-positivist researchers it seems necessary to stop fabricating or upholding a schism between content and affect, between subject and story. Researchers interview the storied subject and act as if the individual is severed from his or her own story, from the emotional aspects of his or her life. Researchers who utilize traditional research protocols are expected to remain severed from their affect, to function within the research relationship as a professionally situated individual with no response or connection to the interviewee's life story. Researchers are expected to act as if they exist in a separate world, slipping in and out of the participant's reality to record discrete bits of information, in order to construct a disinterested (read objective) portrait of the social world.

In keeping with the traditional research preoccupation with "objectivity," most researchers tend to adhere to a trickle-down approach to social research: promoting individual benefit through the advancement of a projected social good. Many researchers are concerned with the potential application of research results in policy and program planning in relation to the needs of the larger community of which the research participant is considered to be a representative member, while neglecting the immediate needs of the individual participant. To ignore the often extensive vulnerabilities and immediate needs of research participants is to justify the advancement of a larger group by the unrecognized sacrifices of members of that same group. It is the interests, therefore, of a wider group, outside those being interviewed, which justify the research.

The use of individuals for the advancement of the "social good" is perhaps the most basic ethical dilemma for social researchers (Melton \& Gray, 1988) who recognize that what is good for the interviewers, the research community, and society in general is not necessarily good for the interviewee. Denial of the needs of individual participants within the research relationship is a rationalization for objectification.

Preventing harm is a researcher's first responsibility. Our contention is that a second responsibility related to the first should be built into research ethics and protocols, that is, that researchers have a responsibility to advocate for participants regarding their immediate needs and long-term goals. When interviewers are addressing sensitive topics and/or working within high-risk communities (two common features in community research work) the ethical principle of "do no harm" may be compromised by research methods which deny the high levels of intersubjectivity inherent in in-depth qualitative interviews. Conducting interviews with vulnerable or at-risk participants such as victims of battering, child sexual abuse, and sexual assault, HIV positive individuals, street youth, the homeless, etc., we assert, requires that researchers deal with the additional element of "need." Participants may request personal support in dealing with traumatic life events, validation of life experiences, answers to practical questions and concerns, and/or information about community resources.

While researchers traditionally record the participants identified needs, the responsibility, as researchers, to act on identified needs has not been well defined and has remained external if not contrary to the research endeavour. What is the responsibility of a researcher, for example, when an HIV-positive youth participating in an AIDS knowledge, attitudes, and behaviour survey incorrectly answers an AIDS knowledge question? Should the priority be to proceed as dictated by 
research protocol without interruption or to address this misinformation in the moment, within the dialogical frame of the research relationship? Traditional research protocols would dictate that interruptions should be avoided at all costs and corrections saved until the formal interview is completed. Pragmatics of this approach, when working with vulnerable and hard-to-reach groups, like street youth for example, need to be closely considered. An important and beneficial component of the interview process, education, and furthermore, empathy, may be unnecessarily lost if the conversational flow within research interviews is inhibited by standard research protocols as discussed earlier in regard to the interviewing experiences of Oakley (1981). Confronted with the immediate needs of research participants, the interviewer is faced with the responsibility to preserve the participant's dignity while providing critical information to individuals who are potentially at risk. A dialogical relationship is necessary between interviewers and interviewees if the interview process is to become an empowering experience. The disclosures and immediate needs of participants should neither be overshadowed by the research agenda nor subverted through the interview protocol.

\section{TRAINING DEFICITS OF RESEARCHERS ENGAGED IN IN-DEPTH INTERVIEWING}

While strategies for eliciting personal disclosures may be very similar within the counselling and research interview, the similarity ends there. Research interviewers are typically not prepared for or trained to respond to the deeply personal disclosures they elicit. While the skills of interviewers are honed to ensure research participants' willingness to talk, conversely, the complementary ability to engage in responsive, dialogical relationships with participants has most often been ignored and discouraged.

On the whole, researchers are untrained to respond to such disclosures and have been traditionally trained to limit and ignore emotional responses to their interview probes. Researchers nevertheless receive and must respond, even if this is a non-response, to the intimate accounts which extend beyond the research frame. A high level of intersubjectivity is inevitable within contemporary social research and, therefore, renders researchers vulnerable to the emotional impact of the personal, often pained, disclosures of their research participants and puts interviewees at risk of disclosing to a researcher who is unprepared and unskilled in receiving such disclosures.

The central concern raised here is the gap which exists between eliciting and responding to disclosures. This gap is illustrated in the following excerpt. Working with children who had witnessed physical abuse, Joyce (journal entry, 1992) remembers the stress of being neither emotionally prepared nor professionally able to respond to the needs of a 9 -year-old boy.

I asked him to play the Family Relations game with me, "Simply mail each card to the person in your family you feel this way about," I instructed him. One of the first cards to appear said, "this person in my family makes me afraid sometimes." Not surprisingly, the child used this opportunity to begin describing how he bad hidden in a closet with his younger sister to escape his dad's violence the right his mom had brought them to the shelter. It still amazes me to this day that I was not prepared to hear his disclosure. Because 
the focus was on children and their peer relationship, I did not expect to contend with children's stories of their mother's abuse since my line of questioning was not about this. Up until that point the only issue anyone, including me, my supervisors and the shelter staff, had been concerned ahout was my need to report any incidents of physical or sexual abuse I might uncover during my interviews. No one thought to discuss the possibility that my questions might lead these children to believe that 1 was an empathetic and skilled listener. My response was a totally discmpowering one, both for the child and for me, I silently ignored the child's story, I thought then, in an attempt to minimize his pain and $I$ moved on to ask the next question.

Higher response rates, minimized "don't know" responses, clarity of questions, and the added benefit of observation make the interviewer an invaluable asset (Berg, 1989) to research teams. Since in-depth interviewing skills have become essential to social researchers; the training of social researchers needs to be reexamined in relation to ethics, interview skills, and appropriate responses to personal disclosures.

Skills training is a central area of concern when examining the ethical responsibilities of social researchers. In comparison to psychotherapists, researchers have few legal obligations placed on them with regard to personal responsibilities in the research setting. Duty to protect potential victims of violence, for example, is a primary responsibility of therapists, one which theorists are beginning to explore as a possible parallel responsibility for researchers who work in the areas of mental health issues (Appelbaum \& Rosenbaum, 1989). Appelbaum and Rosenbaum (1989) propose that an alternative to training social research interviewers about the issues of appropriate crisis intervention and ethical responsibilities is to have clinicians collect sensitive data. This solution seems short term, costly, and an inadequate solution in general. This does not, however, preclude drawing upon the most experienced researchers for participant interface in the data collection stages of a research project, or the development of specialized interviewer training programs and professional-ethical guidelines. Guidelines need to be more than general ideas, they need to include discussion of the grey areas and potential ways of ethically negotiating these grey areas. Increased reflection upon the responsibilities of interviewers and further training in appropriate responses to sensitive disclosures are imperative and attainable goals for social researchers (Patton, 1990; Turnbull et al., 1988).

\section{CONCLUSION}

Qualitative interviewing has proven well suited to the study of the personal and social, however, the qualitative research process bears with it previously unexamined ethical and moral challenges for researchers. Qualitative open-ended interviewing enriches the depth and quality of the researcher's data while at the same time increasing the potential vulnerability of and risk to research participants. While researchers have struggled to balance power and authority within the research relationship through participatory methods, qualitative researchers have, nevertheless, failed for the most part to attend to the immediate needs of their research participants. 
The research relationship can be a very intimate relationship. Research participants may disclose to a researcher things that they have never told anyone before. By acknowledging the highly intersubjective nature of the in-depth interview, researchers, who obtain the "thick" data (Geertz, 1973) characteristic of qualitative research, must learn to anticipate, understand, and respond appropriately to participant disclosures and emotions.

Acknowledging the subjectivity of the interviewee, as we have discussed, extends beyond calling interviewees participants; acknowledging a participant's subjectivity means that researchers acknowledge that interviewees exist in timebefore, during, and after the interview-that the research interview itself becomes part of the individual's life story. Interviewees are thinking, feeling beings who are affected by the research process and who simultaneously affect the researcher. That is to say that the researcher and participant are in a relationship, in an cmbodied reality, in a social world, in which they have an impact on one another.

The research community is beginning to think about additional precautions when conducting social research, specifically when addressing intimate and sensitive topics such as male violence, sexuality, terminal illnesses, and so on (Appelbaum \& Rosenbaum, 1989). Qualitative researchers must challenge those standards of practice which prevent them from acknowledging and responding to participant disclosures and from being aware of and documenting their own responses to the interview process and content. Furthermore, research interviewers must be prepared and trained to act on the self-identified needs and concerns of research participants.

Qualitative interviews are structured to promote disclosures and researchers will, therefore, ultimately receive them. New paradigm research with its increased intersubjectivity and tendency to elicit personal disclosures necessitates a revamping of interview protocols, interviewing skill training for researchers, as well as debriefing and support for both researchers and research participants. Researchers who are concerned with the amelioration of social problems and are committed to doing so, not at the cost of individuals, must also consider the responsibility to advocate for those participants with whom they interface in the research relationship. While researchers cannot and should not take on the role of therapist, they should be cognizant of the fact that the qualitative interview process is fashioned in a strikingly parallel fashion to the counselling interview (Appelbaum \& Rosenbaum, 1989; Glesne \& Peshkin, 1992).

\section{RÉSUMÉ}

Le lien entre le chercheur et le participant dans un cadre de recherche qualitative fait l'objet de la discussion. Nous inspirant de nos expériences de recherches auprès de populations et communautés vulnérables, nous proposons un recadrage du processus d'entrevue. Nous illustrons d'abord la nature changeante et dérangeante de la relation inter-sujets dans un cadre de recherche. De plus, nous proposons qu'il est dorénavant essentiel d'avoir des protocoles de recherche sociale dépassant les simples visées utilitaristes et d'ajouter, au rôle du chercheur, celui de négocier les aspects intersubjectifs de l'entrevue et la défense des droits des participants. 


\section{REFERENCES}

Appelbaum, P.S., \& Rosenbaum, A. (1989). Tarasof and the researcher: Does the duty to protect apply in the research setting? American Psychologist, 44, 885-894.

Babbic, E. (1992). The practice of social research (6th ed.). Belmont, CA: Wadsworth.

Berg, B.L. (1989). Qualitative research methods for the social sciences. Toronto: Allyn \& Bacon.

Burgess, R.G. (1989), Grey areas: Ethical dilemmas in educational ethnography, In R.G. Burgess (Ed.), The ethics of educational research (pp. 60-76). East Sussex, UK: Fainer Press.

Ely, M., Anzul, M., Friedman, T., Garner, G., \& McCormack Steinmetz, A. (1991), Doing qualitative research: Circles within circles. New York: The Falmer Press.

Estroff, S. (1981). Making it crazy: An ethnography of psychiatric clients in an American community. Berkeley: University of California Press.

Geertz, C. (1973). The interpretation of cultures. New York: Basic Press.

Glesne, C., \& Peshkin, A. (Ed5.), (1992). Becoming qualitative researchers: An introduction. White Plains, NY: Longman Press.

Guba, E. , \& Lincoln, Y. (1981). Effective evaluation. San Francisco: Josscy-Bass.

Hall, B. (1975). Participatory research, an approach for change. Prospects, 8(2), 24-31.

Kelman, H.C. (1972). The rights of the subject in social research: An analysis in terms of relative power and legitimacy. American Psychologist, 27(11), 989-1016.

Laing, R.D. (1967). The politics of experience and the bird of paradise, Harmondsworth: Penguin.

Lather, P. (1986). Issues of validity in openly ideological research: Between a rock and a soft place. Interchange, $17(4), 49-84$.

Lather, P. (1991), Getting smart: Feminist research and pedagogy within the post-modem. New York: Routledge.

Lincoln, Y.S., \& Guba, L.G. (1985). Nafuralistic inquiry. Beverly Hills, CA: Sage.

Maguire, P. (1987). Doing participatory research: A feminist approach. Amherst, MA: The Centre for International Education School of Education, University of Massachusetts.

Melton, G.B., \& Gray, J.N. (1988). Ethical dilemmas in AIDS research: Individual privacy and public health. American Psychologist, 43, 60-63.

Mitchell, T. \& Radford, J. (1995), Researching violence in the lives of women and children: Acknowledging and utilizing our feelings as feminist researchers. Trans/forms, 2, 8-18.

Oakley, A. (1981). Interviewing women: A contradiction in terms. In H. Roberts (Ed.), Doing feminist research (pp, 30-61). New York: Routledge \& Kegan Paul.

Patton, M.Q. (1990). Qualitative evaluation and research methods (2nd ed.). Newbury Park, CA: Sage.

Rabinow, P. (1977). Reflections on fieldwork in Morocco. Berkeley: University of California Press.

Rappaport, J. (1990), Research methods and the empowerment social agenda. In P. Tolan, C. Keys, F. Chertok, \& L. Jason (Eds.), Researching community prychology: Issues of theary and methods (pp. 51-63). Washington, DC: American Psychological Association.

Reason, P., \& Rowan, J. (1981). Human inquiry. London: John Wiley \& Sons.

Reason, P. (1988). Human inquiny in action: Developments in new paradigm research. Beverly Hills, CA: Sage.

Reid, M., Landesman Ramey, S., \& Burchinal, M. (1990). Dialogues with children about their families. New Directions for Child Development, 48, 5-28.

Siedman, I.E. (1991), Interviening as qualitative research. New York: Teachers College Press.

Tolan, P., Chertok, F., Keys, C., \& Jason, L. (1990), Conversing about theories, methods, and community research. In P. Tolan, C. Keys, F. Chertok, \& L. Jason (Eds.), Researching communily psychology: lssues of theory and methods (pp, 3-7). Washington, DC: American Psychological Association. 
Turnbull, J.E., McLeod, J.D., Callahan, J.M., \& Kessler, R.C. (1988). Who should ask? Ethical interviewing in psychiatric epidemiology studies. American Joumal of Orthopsychiatry, 58(2), 228-239.

Van Manaan, M. (1990). Researching lived experience: Human science for an action sensitive pedagogy. London, ON: Althouse Press.

Walsh, R.T. (1987). The evolution of the research relationship in community psychology. American Joumal of Communiry Psychology, 15, 773-778. 